\title{
Comparison of Efficiency of Conventional Shaped Circular and Elliptical Shaped Combustor
}

\author{
Dharmahinder Singh Chand ${ }^{1}$, Daamanjyot Barara ${ }^{2}$, Gautam Ganesh ${ }^{3}$, Suraj Anand ${ }^{4}$ \\ ${ }^{1}$ Aeronautical Engineering, Tagore Engineering College, Chennai, Tamil Nadu-600127, India \\ ${ }^{2,3,4}$ Undergraduate Student, Department of Mechanical Engineering. SRM University, Chennai, Tamil Nadu-603203, India
}

\begin{abstract}
There have been concerted efforts towards improving the fuel efficiency of the jet engines in the past, with an aim of reducing the incomplete combustion. The process of combustion in a jet engine takes place in the combustor. A study was conducted for enhancement of air-fuel mixing process by computational analysis of an elliptically shaped combustor for a gas turbine engine. The results of computational analysis of an elliptical shape combustor were compared with a circular shape combustor used in gas turbine engines with a identical cross sectional area. The comparison of the computationally derived parameters of the two combustors i.e. temperature, pressure, and velocity are studied and analyzed. The study intends towards the comparison of the combustion efficiencies of the circular and elliptically shaped combustors. The combustion efficency of elliptical chamber is found to be $98.72 \%$ at the same time it was observed $56.26 \%$ in case of circular type combustor.
\end{abstract}

\section{Introduction}

Since the time aircrafts have taken off, the aviation industry has made strident efforts to upgrade aircraft technology to improve its efficiency. This has led to major advancements in the field of propulsion, aerodynamics, material technology, fuel conservation, etc. The modern day aircrafts have been built while considering these advancements, and performance-wise with significantly high- efficiency standards. However, issues regarding the environmental concerns of pollution and depletion of fuel resources have called for more efforts to be made, especially in the domain of combustion of propulsion system [1].

The combustor is considered as a main component of aircraft, which is responsible for the propulsion of the aircraft. Once aircraft moves forward, the incoming air passes through the engine of the aircraft. The air enters the engine at high velocity and made to pass through the series of compressor blades. The air from the compressor enters the combustor at a high velocity upto $500 \mathrm{ft} / \mathrm{s}$, which is too high for combustion [2]. In order to decrease the air velocity and raise the static pressure, the incoming air is made to pass through the diffuser, before entering the combustor. After passing through the compressor, the velocity of the air decreases significantly, while increasing its pressure. The diffuser is responsible for the reduction in velocity, which helps to maintain a high pressure of the air entering the combustor. This allows for the smooth operation of the engine and flame stability. Usually air-fuel mixture ranges from a ratio $45: 1$ to $130: 1$ [2]. The temperature required for the combustion of the air-fuel mixture lies in the range of $850^{\circ} \mathrm{C}$ to $1700^{\circ} \mathrm{C}$ [3]. The pressure loss in the combustor has to be very minimal. The air entering the combustor passes through two regions, where $20 \%$ of incoming air passes through the snout, while the other $80 \%$ of it passes through the passage between the flame tube body and casing. The air entering the snout, passes through the primary zone. Also the $20 \%$ of air over the flame tube body, enters the primary zone through the primary holes of the flame tube body. The primary zone is responsible for anchoring the flame and attaining sufficient amount of temperature and turbulence for complete combustion of the incoming airfuel mixture [4]. Fuel release occurs at the same time through the flame tube, which results in the formation of a chaotic air-fuel mixture. The turbulence of the flow is generated by the toroidal flow pattern owing to swirl vanes and perforated flare. This recirculation of flow pattern used to allow the continuous combustion of the incoming air and fuel [4]. The temperature of the gases released due to combustion lies between $1800^{\circ} \mathrm{C}$ to $2000^{\circ} \mathrm{C}$ [2]. In the intermediate zone, $40 \%$ of the total airflow enters through the secondary holes, which facilitates in the dropping of the temperature. This drop in temperature allows to complete combustion of $\mathrm{CO}$ and other unburnt hydrocarbons [4]. The combusted gases, then pass through the dilution zone of the combustor. The role of the dilution zone is to allow the air through the tertiary holes in order to meet the wall-cooling's requirements. The temperature of the gases is reduced, as the temperature at which the gases are combusted is too for material to withstand used in nozzle vanes of the 
turbine [4]. The gases exit from the exhaust, after passing through the turbine, thus propelling the aircraft forward.

Hence, it becomes necessary that the combustor's performance is continuously improved. The combustor's efficiency is also directly related to fuel is consumption. The primary considerations of combustor design are ensuring that pressure loss encountered in the combustor is minimized and a high temperature is achieved without compromising with combustion efficiency. While these considerations need to be realized, it must also be ensured that there is efficient fuel consumption and low pollutant emissions [1]. One way to achieve better combustion efficiency is the enhancement of the mixing process. Better mixing helps in producing a better spatial distribution of the air fuel mixture inside the combustor body [5].

The study of non-conventional combustor shapes differs from the conventional design, in terms of mixing and spreading characteristics [6-10]. A change in the cross-sectional shape of the combustor can lead to strong self-induction and instability of vertical structures, which results in a change in the development of the jet, as it expands into its surroundings [5, 8-12].Co-axial jets are capable of producing turbulence and facilitate the massentrainment [6-7, 9-10,13]. Thus, an ellipse is such a shape which has a property to vary the axial flow of air through axis-switching. The mixing and scattering characteristics of the air-fuel mixture will vary for the elliptical combustor. The studies have shown that the jet from the non-circular nozzles produces axial vortices and these vortices are augmented by vortex bending through highly curved flow, thus, increasing the intensity of the small-scale turbulence $[6-8,11]$. The incorporation of the non-circular jets has led to higher combustion efficiency, enhancing combustor performance and reducing the emissions and combustor instabilities [9, 11-12]. This had led to an introduction of the elliptical combustor with elliptically-shaped fuel injector nozzle and elliptical holes over the flame tube. The elliptical combustor which has a variable curvature produces different downstream velocities along its perimeter. The computational analysis is carried out for both the models. The efficiency of the two combustors i.e. conventional and elliptical is compared using the fundamental efficiency formula of the combustors by Ganesan and Yahya [14-15].

\section{Analytical approach}

The tests were performed by modelling the conventional and elliptical combustor models on CAD modelling software. Further, they were analyzed in order to get suitable position for the fuel injector. Combustion simulations were further conducted on the two combustor models to get temperature and pressure profiles, which are to be compared.

\subsection{Modelling of combustor models}

The conventional and the elliptical combustor models were designed using the CAD software, Solidworks 2016.
The circular model is axis-symmetric. Its inner diameter is $128 \mathrm{~mm}$, with a thickness of $1.5 \mathrm{~mm}$ and is modelled over a length of $975 \mathrm{~mm}$. It consists of an inducer inlet, swirler, and fuel injector. The position of the injector is fixed at the point where there is a drop in the Mach number, as compressed air enters the combustion chamber. Similarly, the elliptical model was designed with the same cross-sectional area of conventional model. The fuel injector for both the models is designed as a solid part, aiming that ANSYS FLUENT recognizes the solid part as a fluid region. The CAD models of both the combustors are shown in Fig. 1, Fig. 2, Fig. 3, and Fig. 4 with their corresponding front and side views.

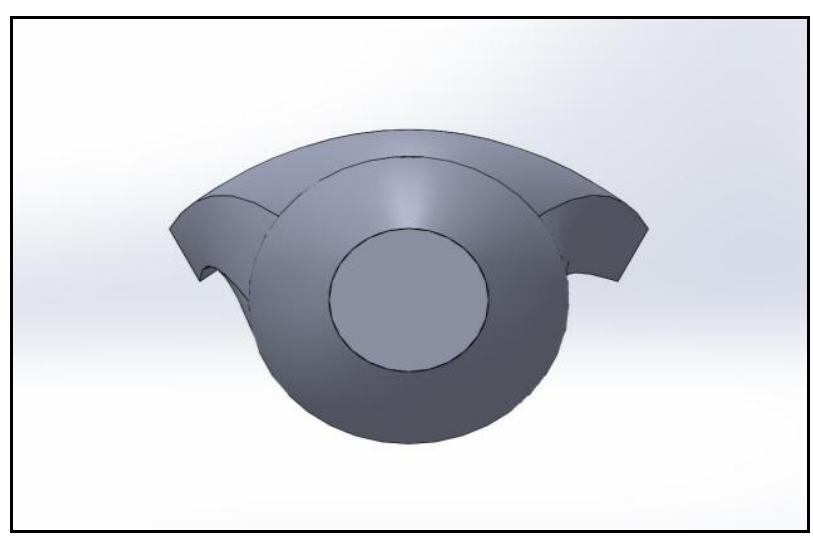

Figure 1.Front View of Conventional Combustion Chamber.

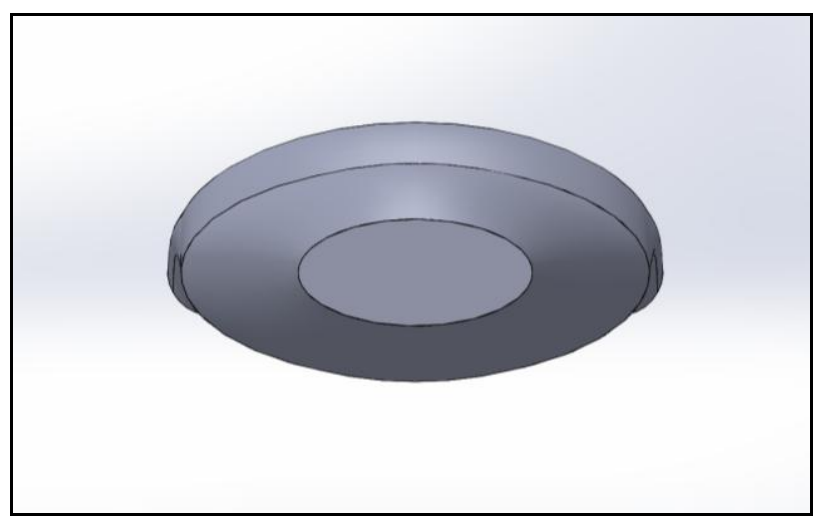

Figure 2. Front View of Elliptical Combustion Chamber.

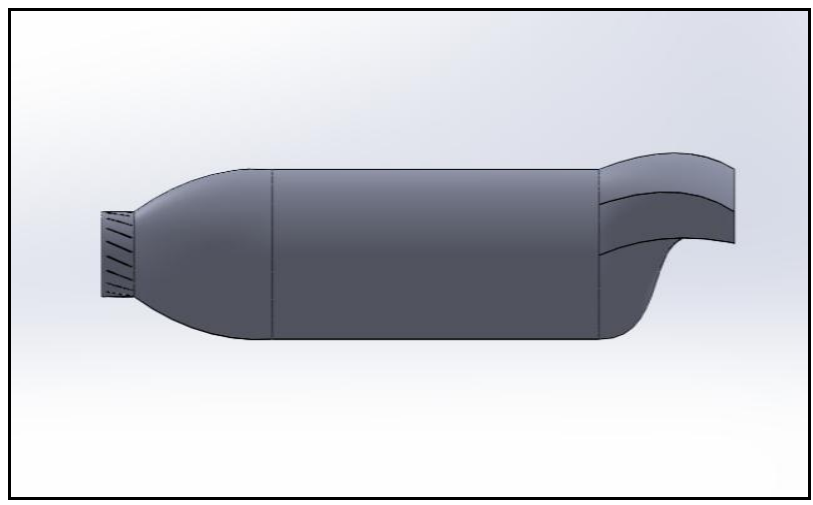

Figure 3.Side View of Conventional Combustion Chamber. 


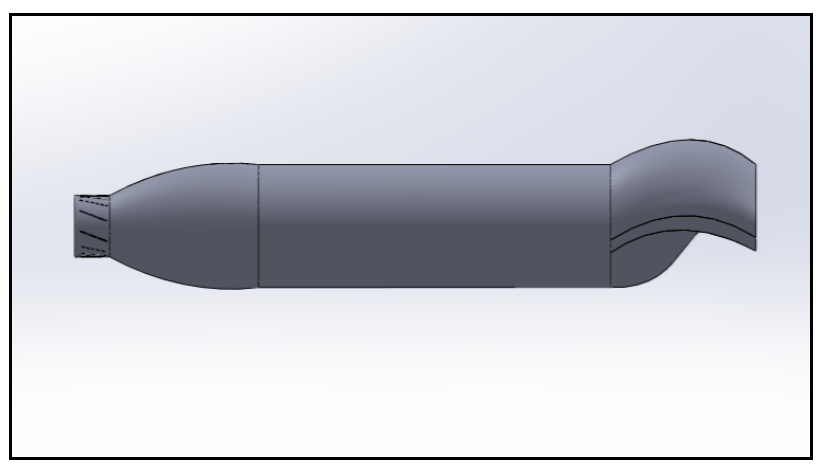

Figure 4. Side View of Elliptical Combustion Chamber.

\subsection{Analysis of the combustors}

\subsubsection{Meshing of the combustor models}

The analysis of the combustion models was performed by ANSYS. The models were imported into the software by saving them in the STEP format. The FLUENT module of ANSYS was used to carry out the analysis. The model was meshed in ANSYS meshing software. A tetrahedral mesh was generated, which was later converted to a Polyhedra mesh. The named selections were made and the mesh file was imported to FLUENT for analysis. The default material used in ANSYS, structural steel, was used as the material of the combustor models. The meshed models of combustors are shown in Fig. 5 and Fig. 6.

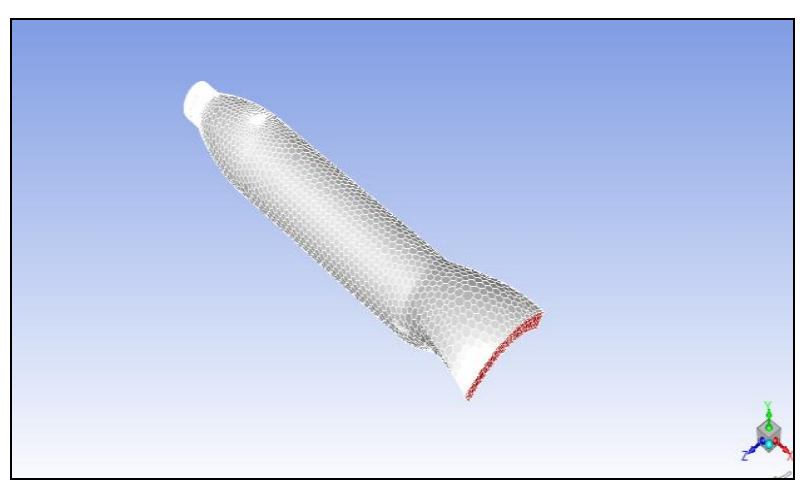

Figure 5. View of the Meshed model of Circular Combustion Chamber.

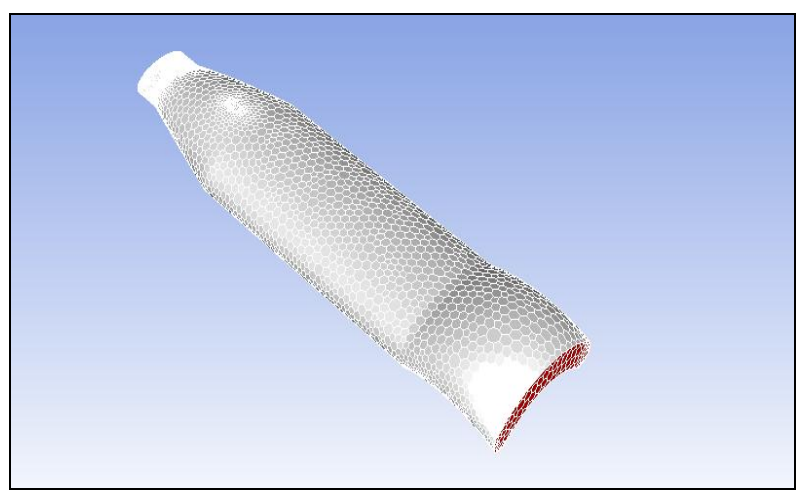

Figure 6. View of the Meshed model of Elliptical Combustion Chamber.

\subsubsection{Fuel injector location}

The meshed models were imported to ANSYS FLUENT for the combustion simulation. The pressure based solver was used since air flow is in a sonic state. The Energy equation and the $\mathrm{k}-\varepsilon$ turbulence model were used. The Radiation P-1 model and a non-premixed combustion method were employed. The air inside the compressor is introduced at Mach 0.3. The location where the Mach number drops is used as a station for the fuel injector. At this the point flow is the more stable, due to gradual drop in velocity of the flow. The Fig. 7 illustrates superimposition of the wireframe model of conventional combustor over the graph, to obtain the location of the fuel injector.

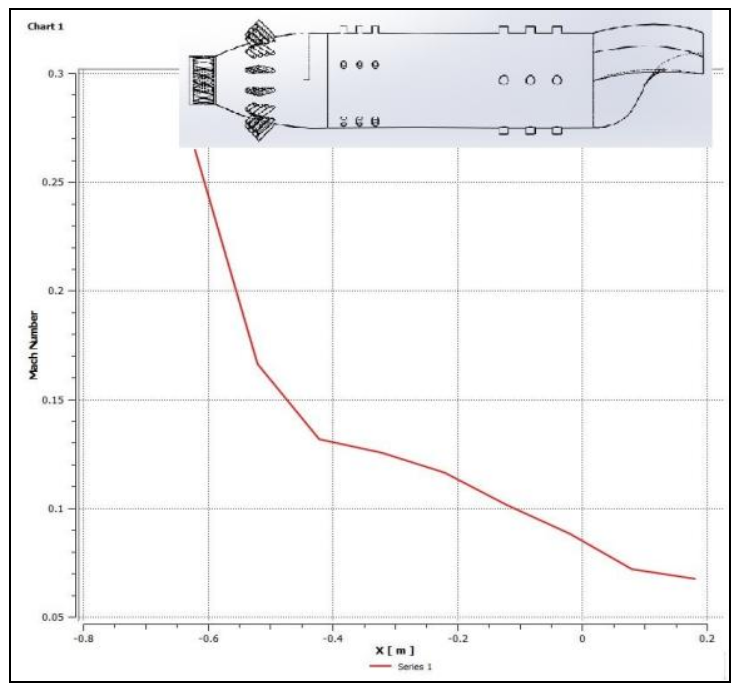

Figure 7. Comparison of the Mach number vs Direction Vector plot with the wireframe model of the Conventional Combustor.

\subsubsection{Combustion process}

Combustion process simulations were to be performed on the circular and the elliptical models. Combustion being the main aspect of the analysis therefore during the course of work the cooling process was ignored. The Jet$\mathrm{a}<\mathrm{g}>$ fuel was used as the fuel for the combustion process. Since the heat addition process in a jet engine takes place at constant pressure, the inlet and outlet pressure conditions were considered invarient as 10 bar. Calculations were carried out for a Mach 0.3 and a stagnation temperature of $288 \mathrm{~K}$. From the calculations, static temperature of the air at the entrance of the combustion chamber was $546.56 \mathrm{~K}$. The mass flow rate of the air was taken as $0.9544 \mathrm{~kg} / \mathrm{s}$. While the static temperature of the fuel inlet was at $300 \mathrm{~K}$ and the mass flow rate of fuel was taken as $0.01908 \mathrm{~kg} / \mathrm{s}$. Using these boundary conditions, the simulations were performed.

\section{Profile analysis}

The combustion simulations of both the combustor models with the suitable input values were executed and the resulting temperature, pressure, and velocity plots were plotted. 


\subsection{Temperature profiles}

The temperature profiles of the circular combustor chamber and the elliptical combustor chamber were retrieved using CFD Post, a post-processing program. The temperature profiles of the circular and elliptical combustor chamber are shown in Fig. 8 and Fig. 9 respectively.

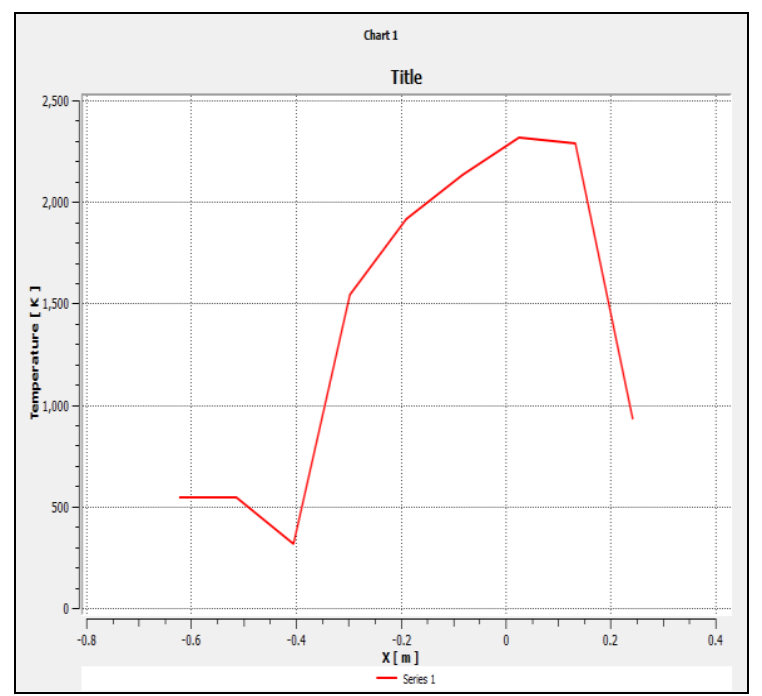

Figure 8. Temperature Profile of Circular Combustion Chamber.

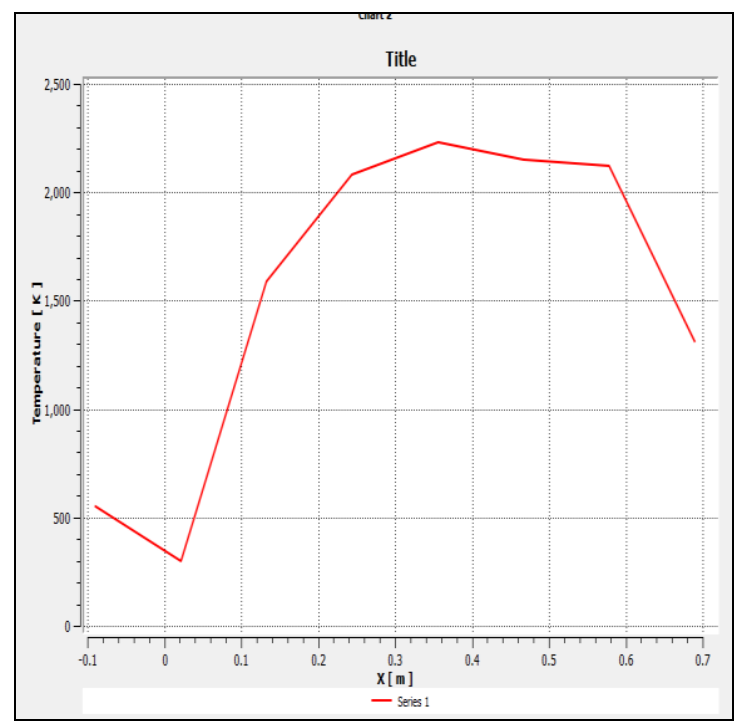

Figure 9. Temperature Profile of Elliptical Combustion Chamber.

Referring to the temperature profiles of both the combustors, it can be inferred that, the temperature at the end of the elliptical combustor is higher than that of the circular combustor. The entrance temperature of the air for both the combustors is same i.e. $546.56 \mathrm{~K}$. The end temperature of the elliptical combustor is $1272 \mathrm{~K}$, while that of the circular combustor is $960 \mathrm{~K}$. The comparatively higher end temperature of the elliptical combustor facilitates higher velocity of the gases at the end of the combustor before entering the turbine.

\subsection{Pressure profiles}

The pressure profiles of both the combustors are depicted in Fig. 10 and Fig. 11.

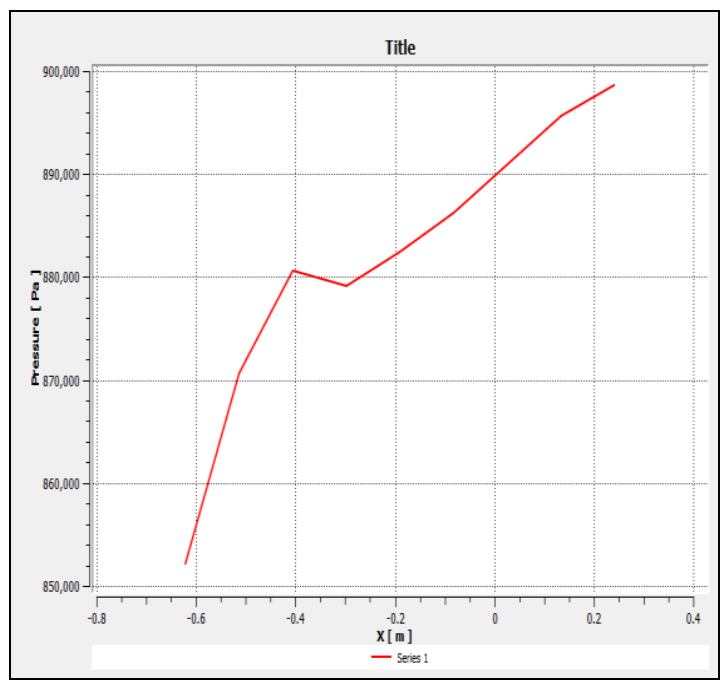

Figure 10. Pressure Profile of Circular Combustion Chamber.

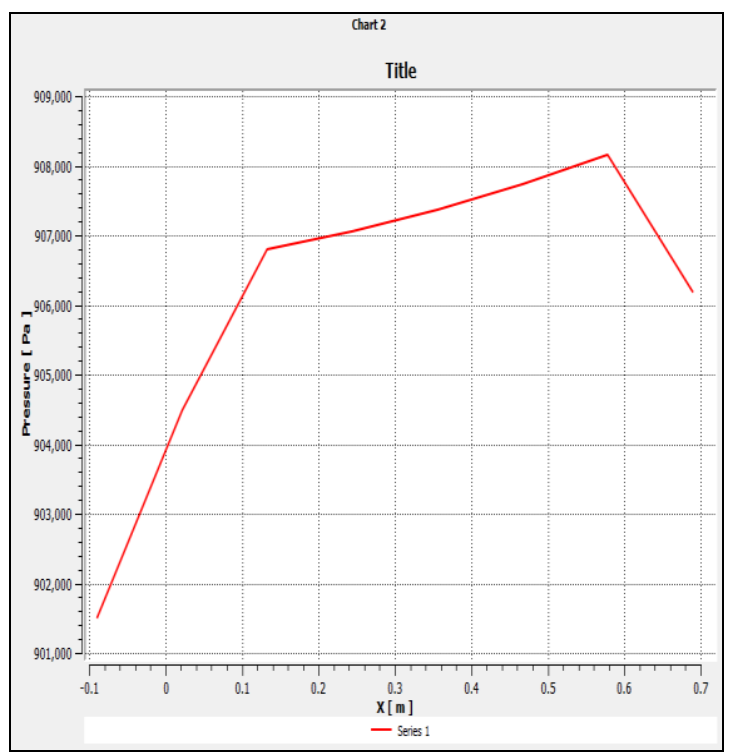

Figure 11. Pressure Profile of Elliptical Combustion Chamber.

One of the requirements of an ideal combustor of a jet engine is to obtain high pressure, without incurring high pressure losses during the process of combustion. It can be inferred from the above profiles that, the pressure achieved in the elliptical combustor is higher than the circular combustor without any occurrence of high pressure drop. There is a need to reduce the pressure loss as the gas turbine engine always operates on the Brayton cycle i.e. constant pressure cycle.

\subsection{Velocity profiles}

The velocity profiles of both the combustors are illustrated in Fig. 12 and Fig. 13. 


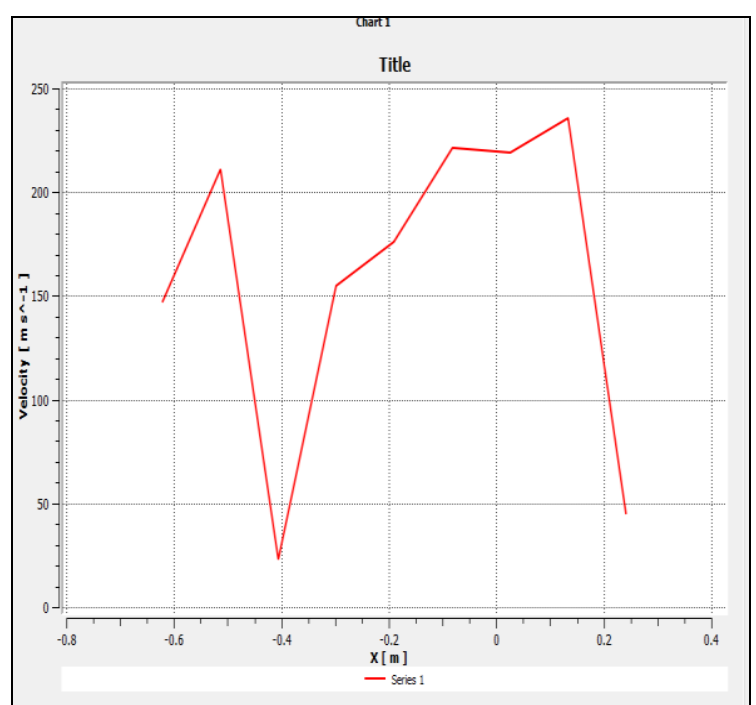

Figure 12. Velocity Profile of Circular Combustion Chamber.

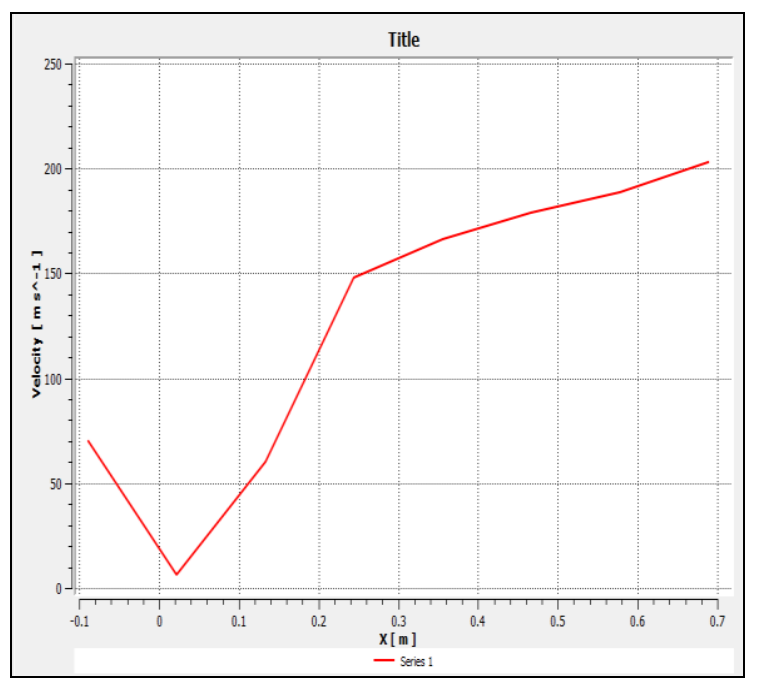

Figure 13. Velocity Profile of Elliptical Combustion Chamber.

The velocity profiles of both the combustion chamber are used to depict the velocity of the gases throughout the combustor along the axial distance. The velocity of both the combustors dip at a point where the fuel injector is placed, as the air and fuel mixture takes place. It can be inferred from the profile that the velocity of the gases at the exit of the elliptical combustor is comparatively, much higher than the circular combustor. The high velocity of the gas is required for producing high thrust and thus propelling the aircraft with a higher thrust.

\section{Calculations}

The combustor efficiency $\eta_{\mathrm{B}}$ of the circular combustor and elliptical combustor is calculated by using following formula [11].

According to formula

$\eta_{B}=\frac{\left(\dot{m}_{a}+\dot{m}_{f}\right) * C_{p}}{\dot{m}_{f}^{*} C . V} \frac{T_{03}}{-} \underline{T}_{02} \underline{L}$

where,

$\dot{\mathrm{m}}_{\mathrm{a}}=$ Mass flow rate of air, $\dot{\mathrm{m}}_{\mathrm{f}}=$ Mass flow rate of fuel,

$\mathrm{C}_{\mathrm{p}}=$ Specific heat at constant pressure $=1147 \mathrm{~J} / \mathrm{kg} . \mathrm{K}$, C.V $=$ Calorific Value of fuel $=43 * 10^{6} \mathrm{~J} / \mathrm{kg}$,

$\mathrm{T}_{02}=$ Stagnation Temperature at the Combustor Inlet,

$\mathrm{T}_{03}=$ Stagnation Temperature at the Turbine Inlet.

\subsection{Combustion efficiency of circular combustion chamber}

The temperature at the inlet of the circular combustor is $546.56 \mathrm{~K}$ and at the inlet of the turbine/ exit of the combustor is $960 \mathrm{~K}$ by referring to the plot of the temperature curve for a circular combustor as shown in Fig. 6. The mass flow rate of air is $0.9544 \mathrm{~kg} / \mathrm{s}$. The mass flow rate of the fuel is $0.01908 \mathrm{~kg} / \mathrm{s}$. The combustor efficiency of the circular combustor is given by substituting the values in formula (1),

$$
\begin{aligned}
\eta_{\text {Bcircular }} & =\frac{(0.9544}{+0.01908) * 1147 *(960-546.56)} \\
& =0.01908 * 43 * 10^{6} \\
& 0.5626 \text { or } 56.26 \%
\end{aligned}
$$

\subsection{Combustion efficiency of elliptical combustion chamber}

Similarly, the temperature at the inlet of the elliptical combustor is $546.56 \mathrm{~K}$ and at the inlet of the turbine/ exit of the combustor is $1272 \mathrm{~K}$, by referring to the plot of temperature curve for an elliptical combustor as shown in Fig. 7. The mass flow rate of air is $0.9544 \mathrm{~kg} / \mathrm{s}$. The mass flow rate of the fuel is $0.01908 \mathrm{~kg} / \mathrm{s}$. The combustor efficiency of the elliptical combustor is given by substituting the values in formula (1),

\section{$\eta_{\text {Belliptical }}=\frac{(0.9544}{+0.01908) * 1147 *(1272-546.56)}$$$
=0.9872 \text { or } 98.72 \%
$$

\section{Conclusion}

It is evident from the calculations and the profiles of combustors that, the variation in temperature, pressure, and velocity are caused due to the change in the shape of the combustors. The improvement in these computationally derived properties of the elliptical combustors is because of the axis-switching phenomenon. The increased velocity and temperature is facilitated by the higher turbulence in the elliptical combustion chamber. The axis switching phenomenon definitely plays a vital role in enhanced mixing of elliptical combustor. Therefore combustion efficiency of elliptical type is more than that of the circular type combustion chamber.

\section{References}

1. Wajid.A.Chishty and Manfried Klien, 'Combustion and Emission Issues in Gas Turbines', $19^{\text {th }}$ Oct 2009.

2. Rolls-Royce plc, 'The Jet Engine', ISBN 0902121235 (1986). 
3. H S Mukunda, 'Understanding Combustion', (1989).

4. A.H. Lefebvre and D. R. Ballal, Gas turbine combustion. CRC Press, (2010).

5. D. Wager, 'The Influence of Elliptical Nozzle Holes on Mixing and Combustion in Direct Injection Natural Gas Engines'.

6. E. Gutmark, K. C. Schadow, and K. J. Wilson. 'Subsonic and supersonic combustion using noncircular injectors', Journal of Propulsion and Power, Vol. 7, No. 2 (1991), pp. 240-249.

7. Mohsen Akbarzadeh, Madjid Birouk, 'Liftoff of a Co-Flowing Non-Premixed Turbulent Methane Flame: Effect of the Fuel Nozzle Orifice Geometry'. Flow, Turbulence and Combustion 92:4, 903-929, (2014).

8. Miler, R.S., Madnia, C.K. \& Givi.P., 'Numerical Simulations of non-circular jets', Computers \& Fluids 24, pp1-25, (1995).

9. Husain H.S. \& Hussain F., 'Controlled excitation of elliptic jets', Physics of Fluids, 26, pp2763-2766, (1983).
10. Ho, C.M. \& Gutmark, E.,'Vortex induction and mass entrainment in a small-Aspect-ratio elliptic jet', Journal of Fluid mechanics, 179, pp383-405, (1987).

11. Gutmark, E., Schadow, K.C., Parr, T.P., HansonParr, D.M., \& Wilson, K.J., 'Noncircular jets in combustion systems', Experiments in Fluids 7, 1989,pp248-258.

12. E.J.Gutmark, F.F.Grinstein, 'Flow Control with Non Circular Jets', Annual Review of Fluid Mechanics 31(1):239-272, (2003).

13. N L Narasimha Reddy, P Manivannan,K M Kiran Babu, 'The CFD Analysis of Turbulence Characteristics in Combustion Chamber with Non Circular Co-Axial Jets', IOSR-JMCE, Vol.6, Issue 2, pp 01-10.

14. V. Ganesan, 'Gas Turbines', Tata McGraw Hill Publishing Co., New Delhi, (1999).

15. S. M Yahya,'Fundametals of Compressible Flow with Aircraft and Rocket Propulsion', New Age International Publisher, New Delhi, (1982). 